\title{
TECNOLOGÍAS DE LA INFORMACIÓN Y LOS MENSAJES EN LOS NUEVOS ESPECTROS DEL CONFLICTO.
}

\section{INFORMATION TECHNOLOGIES AND MESSAGES IN THE NEW SPECTRUMS OF THE CONFLICT.}

Jacinto Gómez López, Universidad Complutense de Madrid, España. jacintog@ucm.es

Código ORCID: 0000-0002-7754-938X

\section{RESUMEN}

El desarrollo de las tecnologías de la información ha impactado en las sociedades, más allá del ámbito geográfico, a lo largo de la historia. Uno de los principales actos humanos es el conflicto, que no es sino una serie de acciones que persiguen objetivos políticos o económicos, a través de unos medios, que en ocasiones son de carácter pacíficos pero que en otras pueden llegar a los bélicos, como la guerra. En desarrollo temporal de los conflictos se observa que el uso de la comunicación ha sido paralelo al desarrollo de las tecnologías de la información, siendo hasta la última revolución similar en planteamientos. Con la llegada de la revolución digital se transforma el panorama mediático, pero a su vez han aparecido nuevos tipos de conflictos que son diferentes a los que históricamente han existido. En esta investigación se analizan los cambios producidos en los nuevos conflictos y se analizan tres escenarios bélicos del siglo XXI. También se expone que tipo de impacto tiene en cada sociedad y como se vehicula el mensaje a través de las tecnologías de la información, estudiando las características de los mensajes, públicos a los que se dirige y tipos de soportes utilizados.

PALABRAS CLAVE: Tecnologías de la Información, guerra, híbrida, internet, redes sociales, revolución digital, audiencia.

\section{ABSTRACT}

The development of information technologies has impacted societies, beyond the geographical scope, throughout history. One of the main human acts is the conflict, which is nothing more than a series of actions that pursue political or economic objectives, through means that are sometimes peaceful but in others can reach the war. In the temporal development of conflicts, it is observed that the use of communication has been parallel to the development of information technologies, with the latest revolution being similar in approaches. With the advent of the digital revolution the media landscape is transformed, but in the same time new types of conflicts have appeared that are different from those that have historically existed. In this research, the changes produced in the new conflicts are analyzed, and specially we look into three war scenarios of the 21st century. It also shows what kind of impact it has on each society and how the message is carried out through information technologies, studying the characteristics of the messages, the target audiences and types of media used. 
KEY WORDS: Information Technologies, war, hybrid, internet, social networks, digital revolution, audience.

\section{Cómo citar el artículo:}

Gómez López, J. (2019). Tecnologías de la información y los mensajes en los nuevos espectros del conflicto. Revista de Ciencias de la Comunicación e Información, 24(2), 45-56. doi: http://doi.org/10.35742/rcci.2019.24(2).45-56

\section{Introducción}

En la actualidad están apareciendo informaciones en diferentes medios de comunicación sobre los nuevos conflictos híbridos. De su lectura el público puede llegar a entender que son nuevos tipos de conflicto, quizás menos generalizados, o incluso de carácter social.

Si se busca el significado de conflicto en la RAE encontramos varias acepciones, 6, siendo la primera de ellas "Combate, lucha, pelea. U. t. en sent. fig.". En el caso de híbrido dispone de 4 acepciones, siendo su segunda acepción "2. adj. Dicho de una cosa: Que es producto de elementos de distinta naturaleza." Por otra parte si atendemos a la definición de Colom Piella, Guillem (Colom Piella, 2014) “...un nuevo tipo de conflicto que combina el empleo de medios irregulares y convencionales limitados..."

Por lo que se observa que ha aparecido un nuevo concepto que escapa al tradicional conflicto armado. Y escapa motivado por la aparición de nuevos elementos que son utilizados como un nuevo tipo de armas. Y este contexto aparece el concepto del uso de la información (Simon, 2016).

Se puede deducir que el uso de la información en este nuevo tipo de conflicto tiene como fin influir en la toma de decisiones y ganar el apoyo de la población, para la obtención de determinados objetivos. Para lo cual se utilizarán todos los soportes posibles: radio, televisión, periódicos, panfletos, carteles o Internet, y especialmente los medios locales con personal nativo, para hacer llegar mejor los mensajes a la audiencia objetivo.

Las características principales de este nuevo tipo de conflictos son las siguientes:

- La decisión del conflicto se busca principalmente en un centro de gravedad no militar.

- Las líneas tradicionales de orden y responsabilidades están siendo desafiadas a través de operaciones contra vulnerabilidades del oponente a la sombra de diferentes interfaces.

- A través de la combinación de diferentes conceptos, métodos y medios, aparecen "nuevas" formas de guerra y evolución del combate.

Por lo tanto, el conflicto híbrido emplea una amplia variedad de instrumentos: fuerza militar, tecnología, crimen, terrorismo, economía y presiones financieras, medios humanitarios y religiosos, inteligencia, sabotaje, desinformación - a través de todo el espectro del conflicto: tradicional, irregular y / o catastrófico.

Y para vehicular los mensajes que sirven de apoyo a lo anteriormente señalados es necesario el uso de las tecnologías de la información.

Revista de Ciencias de la Comunicación e Información, Vol. 24, № 2, 45-56 


\section{Jacinto Gómez López}

\section{Breve repaso cronológico.}

El uso de la información como herramienta de obtención de objetivos en las diferentes audiencias no es nuevo.

Uno de los primeros ejemplos es el de la batalla de Kadesh, en el Egipto de faraón Ramses II (Pérez Lagarcha, 2009), en el que la propaganda egipcia minimiza el resultado de la misma, llegándose a entender que fue una victoria del faraón por el análisis de las imágenes de su palacio en Egipto.

Otro de los ejemplos del uso de la comunicación es el de Julio César y su Guerra de las Galias (Ames, 2003-2004). En esa obra se proclaman las virtudes del futuro dictador de Roma.

Se podría continuar con la Leyenda Negra (SCHULZE SCHNEIDER, 2008) de España durante y posteriormente a la guerra de Flandes para finalizar con la propaganda de la segunda guerra mundial (Pizarroso Quintero, 2009).

Pero la característica que ha definido a estos conflictos es la linealidad, entendida como el choque entre contendientes que son iguales. Y se entiende por iguales por el uso de la fuerza desde un punto de vista conceptual.

En cambio, con la llegada del nuevo siglo algo ha cambiado. Por un lado, la aparición de un nuevo tipo de tecnología de la información, que esta vehiculada por internet permitiendo el acceso, de momento, a la audiencia a múltiples canales de información y por otro lado a la generación libre de contenidos, y por otro el nacimiento de un nuevo tipo de conflicto, el denominado híbrido.

Es necesario apuntar que el comienzo de este nuevo concepto, guerra híbrida y uso de la información como "otra" herramienta más, lo define el Departamento de Defensa Norteamericano ([DoD], 2005) en 2005 que explica la combinación de dos o más amenazas de tipo tradicional, irregular, catastrófico o disruptivo, en el conflicto de Chechenia. Desde un punto de vista teórico fue desarrollado por el general James Mattis, Secretario de Defensa de Estados Unidos con el Presidente Trump, y el teniente coronel Frank G. Hoffman (MATTIS, 2005).

En el año 2006 estalla el conflicto entre Israel y Hezbollá y en el que se aplica lo anteriormente descrito, para en conflictos posteriores, Balcanes, Chechenia, Afganistán, Irak, Líbano, Siria o el Estado Islámico, se convirtiera en norma.

\section{Uso de la tecnología de la información en los conflictos híbridos.}

Es necesario describir que el uso de la información como herramienta cada vez más importante ha ido a caballo del desarrollo de las tecnologías de la información, y por otra parte de la alfabetización digital de las sociedades.

Se va a describir el uso de las tecnologías de la información en tres conflictos diferentes, tanto de épocas como de contexto social. Se hace hincapié en el caso afgano por su especial idiosincrasia. 


\section{TECNOLOGÍAS DE LA INFORMACIÓN Y LOS MENSAJES EN LOS NUEVOS ESPECTROS DEL CONFLICTO.}

\section{Chechenia.}

Tal y como defiende James Mattis Chechenia fue el primer conflicto híbrido, si no en su primera fase si en la segunda.

En el caso de Chechenia esta tuvo dos capítulos diferenciados en el tiempo:

1. Primera guerra de Chechenia. (1994 - 1996)

Desde el enfoque de la tecnología de la información en ese periodo temporal las principales tecnologías son, la prensa escrita, radio, televisión. En 1995 aparece TheGlobe.com, pero no existe un panorama de medios digitales.

Por lo tanto, la información era controlada por uno de los contendientes del conflicto, en este caso la parte rusa.

2. Segunda guerra de Chechenia. (1999-2009)

En este espacio temporal aparece internet, la web 1.0 en la que los mensajes son unidireccionales para posteriormente evolucionar a la web 2.0, o la era de las redes sociales.

De la primera no se puede afirmar que se obtuviera información hacia el exterior que no hubiera pasado el crisol de las autoridades rusas, como consecuencia de las tecnologías de la información imperantes en la época. Por lo tanto, el uso de la información como herramienta del conflicto es residual.

En la segunda guerra el panorama de la información ha cambiado drásticamente como consecuencia de la aparición de internet, tanto en su versión web 1.0 como 2.0.

En este capítulo del conflicto el uso de la información es profuso por parte de los contendientes.

La principal diferencia es la aparición de un soporte de información que no es controlado por el estado ruso y que comienza a ser utilizado por parte de los chechenos.

El principal portal por el que comienzan a vehicular su mensaje es la página web, https://www.kavkazcenter.com. Esta dispone de una página de inicio en la que te facilita el acceso en diversos idiomas, ruso, inglés, árabe y turco. Por lo que se deduce que la intención del editor es internacionalizar el conflicto, fundamentalmente en su contexto cultural, árabe y turco.

En ella encontramos diferentes secciones de opinión y se encuentran disponibles diferentes archivos multimedia, videos y fotos. La estructura es la de un medio de comunicación estándar, diferentes secciones con artículos de opinión, artículos de formación y propaganda de su causa. Dispone de una sección de videos donde se puede encontrar declaraciones de sus líderes. Se comprueba que la audiencia objetiva es la comunidad cercana y musulmana.

\section{Estado Islámico}

Estado Islámico de Irak y el Levante, también conocido como Estado Islámico de Irak y Siria o EIIL, oficialmente Califato Islámico,4712 conocido también como Estado Islámico, ISIS o El (en árabe, الإسلامدية الدولة, ad-dawla al-islāmīya), o como Dáesh o Daish 


\section{Jacinto Gómez López}

(Fundéu, 2014), es un fenómeno que nace como consecuencia de la descomposición de Iraq con posterioridad a la guerra.

En este conflicto se observa un cambio en relación al uso de las tecnologías de la información y los públicos que se buscan.

Por una parte, se observa que los mensajes que emiten, son de tipo profesional, como se pueden dar en la sociedad occidental. Se nota que los comunicadores del ISIS han sido formados en occidente.

Tal es la importancia que se le otorga a la comunicación que se establece una especie de ministerio, liderado por el considerado ministro de Comunicación Abu Mohamed al Furqan, jefe de operaciones de medios de comunicación (Moore, 2016), con diversas ramas (Carrión, 2016), como:

- Al Furqan: División en árabe. Rama primigenia que produce videos en árabe.

- Al Hayat: División en no árabe. Produce contenido escritos y audiovisuales hasta en 16 idiomas.

- Al Bayan: Emisora de radio. Sobre todo, en árabe, tiene boletines en inglés, francés o ruso.

- Al Naaba: Revista semanal en árabe para la población del califato.

- Ajnad: Produce el nashid, cantico religioso que vende bondad y alimenta el ardor guerrero.

- Al Amaq: Agencia de noticias que los yihadistas no vinculan a su estructura oficial.

Por lo tanto, se observa la importancia que se le da por parte de los dirigentes de esta organización terrorista a la vehicularían de mensajes, desde la creación del primer departamento, Al Furqan, en 2006.

De su estructura se deduce que tiene interés en que su mensaje llegue a diferentes audiencias.

Al Hayat, su división no árabe, dispone de soporte para 16 diferentes lenguas, para que su mensaje llegue a diferentes regiones de mundo con, por un lado, labor de captación y por otro el objetivo de producir inquietud en dichas sociedades que logren determinados objetivos políticos, siendo el más claro la influencia de sus gobiernos.

En el año 2015, momento de mayor expansión territorial, se intentó por parte de este grupo de la creación de un canal de televisión BEIN HD4, no logrando resultados positivos.

Por otra parte en su esfuerzo por generar contenido el ISIS o DAESH publicó en 2017 una infografía en el que afirmaba que el esfuerzo mediático realizado en tres años era de infografía el esfuerzo mediático realizado en los tres años de vida del califato y aun poniendo en cuestión la veracidad absoluta de las cifras que ofrece, su magnitud resulta significativa: más de 41.230 mensajes emitidos, que se desglosan de la siguiente manera: 1.670 mensajes de audio, 2.880 videos, 4.540 comunicados escritos y 32.140 reportajes fotográficos (Ballesteros Martín, 2017).

En relación a las redes sociales el DAESH el DAESH lanza una media de 35 comunicados dirigidos a sus partidarios, que abren diariamente más de 1.000 cuentas 


\section{TECNOLOGÍAS DE LA INFORMACIÓN Y LOS MENSAJES EN LOS NUEVOS ESPECTROS DEL CONFLICTO.}

diarias y publican en redes sociales como Twiter, Facebook, Google+o Instagram (Gluck, 2017).

Dentro de las redes sociales es notorio el uso de la red social Telegram por parte del DAESH. Esta tiene la característica de implementar un protocolo propio, MTProto, que transmite los mensajes de forma segura entre nuestro móvil y el servidor. Incluso permite crear chats seguros entre dos clientes, de tal forma que ni siquiera los servidores de Telegram pueden ver qué estás enviando, por lo que sirve para las comunicaciones en la red profunda, ya que permite el empleo de un servicio encriptado de carácter anónimo. Como diariamente se cierran miles de cuentas, y los estrategas de comunicación de la organización lo saben, utilizan los "Hashtag" y las palabras clave como elemento de enganche para que sus seguidores encuentren las nuevas cuentas.

Mención especial merece la revista DABIQ. El nombre de la misma proviene del nombre de la ciudad siria de Dabiq en la provincia de Alepo, ya que según la tradición islámica allí tendrá lugar la batalla final entre infieles, mayoritariamente cristianos y los ejércitos musulmanes, cuya victoria dará lugar al califato universal con la caída de Roma, como capital de la cristiandad. y la conquista de Constantinopla (Estambul), según el periodista Gwynne Dyer (Dyer, 2015).

En el primer número presenta a la yihad como instrumento para alcanzar el califato universal, y para que no quepa ninguna duda la define como "La Yihad se basará en la hijrah (emigración), lealtad al líder, obediencia, entrenamiento, lucha y Khilafa (Califato) o Shahada (No hay más Dios que Alá y Mahoma es su profeta)". (The Return of Khilafah, 2014)

Por lo tanto es usado con herramienta para dirigir mensajes a la población que se encuentre para su gobierno directo, como en DABIQ 1 en que publica "El Estado Islámico tiene una extensa historia construyendo relaciones con las tribus dentro de sus fronteras en su intento de fortalecer las filas de los musulmanes, unirles bajo un imán y trabajar juntos por el establecimiento del califato" (The Return of Khilafah, 2014), otros pueblos musulmanes y que quiere unir a su causa como publica en su número 4 que Ansar alIslam anuncia su jura de lealtad al Estado Islámico donde se puede leer: "Este es el Estado que abrió las tierras del islam, erradicó las fronteras artificiales entre los musulmanes, rompió los grilletes de los prisioneros y liberó a los leones" (The Failed Crusade, 2014) y en posteriores números, y dirigido a la población de estados no musulmanes, con la publicación de "Just Terror" (Just Terror, 2015) tras la intervención rusa en Siria sobre el derribo de un avión chárter ruso sobre la península del Sinaí y tras el atentado de la sala Bataclán en Paris.

Esta estrategia continua de "The Murtadd Brotherhood" tras los atentados de Bruselas de abril de 2016, en el que afirman "Los occidentales caerán, con estos atentados debilita su economía, traumatizan a sus ciudadanos... Todos los países están en riesgo, París fue un aviso. Bélgica el recordatorio". (The Murtadd Brotherhood, 2016)

Con la caía de la ciudad de Dabiq en manos turcas paso a titularse Rumiya (Roma) con el fin de recordar el último objetivo de la organización.

Como se comprueba en el conflicto sirio e iraquí una de las principales herramientas que uso el DAESH fue la comunicación, con el uso de todas las tecnologías de la información disponibles, y dirigido a toda su audiencia objetiva, la población del terreno conquistado, 


\section{Jacinto Gómez López}

la población y organizaciones que se presumen puedan ser afines fuera de los territorios bajo su gobernanza y la población de los países que la combaten, fundamentalmente cristianos.

Es por tanto necesario que esa audiencia tenga un nivel de alfabetización digital mínimo para que los mensajes les puedan llegar, y que en los territorios a los que dirigen los mensajes sí que disponen de la misma. Incluso en los niveles inferiores de alfabetización dispone de una emisora de radio, Al Bayan, para hacerles llegar sus mensajes.

\section{Afganistán}

En el caso de este país es necesario conocer su contexto físico y humano.

Físicamente se encuentra el continente de Asia y limita con China, Irán, Pakistán, Tayikistán, Turkmenistán \& Uzbekistán, sin salida al mar y montañoso.

Desde un punto de vista humano es una sociedad multiétnica y tribalizada. La población se divide en diferentes grupos etnolingüísticos siendo los principales los pastunes, tayikos, hazaras, uzbekos. De acuerdo al ranking del índice de desarrollo humano (Programme, 2018) sus habitantes se encuentran en el puesto 168, por lo que sus habitantes están entre los que ocupan peor lugar.

Por lo tanto, el contexto es claramente de poca introducción y acceso de la comunicación digital por amplias capas de la población. De ahí que el uso de las tecnologías de la información en el conflicto sea diferente. Parece evidente que su uso será más físico y menos digital, al menos para la audiencia interior, siendo el uso de las nuevas tecnologías reservada para la audiencia externa.

En el caso de la audiencia en su territorio, los mensajes gubernamentales se realizan a través de los medios de comunicación oficiales y para la población que vive fuera de las ciudades, se intenta vehicular a través de los consejos de ancianos de cada una de las aldeas. En cambio, los mensajes de los grupos insurgentes se realizan con otro tipo de vehículos.

El tipo de comunicación más usado es de las cartas nocturnas.

Se tiene conocimiento que los insurgentes han utilizado repetidamente, con el tiempo, un peculiar instrumento de comunicación: las cartas nocturnas. Estos son textos de longitud variable, generalmente expresando una advertencia o un comunicado a la población de hacer o no hacer algo.

Estos documentos se publican, para que sean claramente visibles, en un lugar céntrico o simbólico de la comunidad, como la puerta o la pared de la mezquita u otro edificio público.

La estructura de la carta nocturna, o night letter (Canada, 2015), es muy simple. Después del encabezado, como el del Emirato (es decir, régimen talibán), continua con un mensaje de propaganda consistente en uno parte introductoria, más o menos densa, con referencias coránicas o poéticas, y una parte de la expositiva, es decir, una orden o prohibición destinada a dirigir la conducta de los residentes locales con indicación de las consecuencias para aquellos que no las siguieran. A veces, al finalizar el texto, se introduce un párrafo, conteniendo referencias a la memoria de los mártires. 


\section{TECNOLOGÍAS DE LA INFORMACIÓN Y LOS MENSAJES EN LOS NUEVOS ESPECTROS DEL CONFLICTO.}

Los casos varían e incluyen instrucciones para los residentes en las aldeas, con el fin de que dejen de mantener relaciones con instituciones gubernamentales, con las fuerzas de la coalición y organizaciones no gubernamentales occidentales.

Otro de los casos es la imposición de impuestos con indicación de la llamada autoridad en cuyo nombre la milicia pueda cobrarlos; los llamamientos para unirse a las milicias en la lucha contra el gobierno de Afganistán y sus aliados; los llamamientos a la Yihad militar explícitamente contra los "cruzados occidentales".

Independientemente del mérito del mensaje, es necesario reflexionar sobre medios específicos utilizados por los insurgentes para comunicarse con los habitantes de la aldea. En un examen superficial, de hecho, podría ser difícil de entender la elección de un texto escrito para guiar la conducta de una población.

Ampliamente analfabetos (Instituto de Estadística de la Organización de las Naciones Unidas para la Educación, 2018), en el caso de las comunidades rurales, podría de hecho, parecer ilógico escribir una carta a un grupo humano que en el su casi totalidad no tiene las habilidades alfabéticas para leerlo. En ese contexto un observador podría caer en un prejuicio etnocéntrico.

De lo anterior se podría deducir que las comunicaciones por parte de las partes en conflicto no utilizan la palabra escrita, sino otro tipo de tecnologías o soportes, que utilicen códigos de representación "no alfabéticos", como las visuales (dibujo, fotografía). Pero paradójicamente, es la tradición oral, es decir, ese sistema de transmisión de conocimientos que permite la circulación horizontal, (síncrona) y la transferencia vertical (diacrónica, de una generación a la otra), del conocimiento dentro de sociedades simples o sin escritura, la que en estos contextos sociales permite que la información sensible, es decir, la información de la que depende la continuidad moral y material (léase: supervivencia) de la comunidad se transmita utilizando unidades narrativas como vehículos.

Estas unidades narrativas son repetidas indefinidamente (cuentos, fábulas, mitos, proverbios, canciones, poemas, parábolas, disculpas) en ocasiones como, ritos culturales y actuaciones, tanto de carácter público (funciones, ceremonias que involucran al conjunto de la comunidad o gran parte de la misma), así como privado (conversaciones con amigos, formas de entretenimiento doméstico, ocurrencias, etc.).

Las campañas de información, no conducidas por las tecnologías de comunicación tradicionales y digitales de los medios de comunicación masivos, ofrecen la característica de no saturar de información el ambiente y que el mensaje se vincule a la unidad narrativa. Solo la información contenida dentro de las unidades narrativas consistentes en la consolidación de la ética y épica de la comunidad, puede aspirar dentro de ella, a una amplia difusión. No toda la información, obviamente, se vincula de la misma manera. La información que se comunica para ser incorporados a la raíz de una historia, o un fragmento de la misma, de una forma atrayente para que sea difundida / entregada (del latín tradere, entregar, desde la cual, precisamente, traditio) tiene la posibilidad de alcanzar la máxima audiencia en un tiempo menor, mientras que aquellas que se vehiculan fuera del esquema de la tradición, apenas se propagarán.

Estas son las razones que inducen a los talibanes, uno de los grupos insurgentes en conflicto, de una forma consciente, a confiar su comunicación operativa a los textos, Revista de Ciencias de la Comunicación e Información, Vol. 24, № 2, 45-56 


\section{Jacinto Gómez López}

escritos principalmente en el estilo de la fatwa (frase de la sharia), del anatema (maldición), o de la disculpa (cuento moral). Estos textos, a través de los alfabetos de la comunidad (objetivo intermedio), continúan circulando oralmente, de una forma esencialmente narrable, consiguiendo un efecto de propagación viral absolutamente eficiente, en relación con el contexto.

Un producto visual (dibujo, fotografía), en el contexto de una comunidad en la cual los mecanismos de la tradición oral siguen siendo efectivos, no podrá disfrutar de la misma efectividad de un producto narrativo, por dos razones.

1) La primera razón es de carácter general, y procede de la estructura semántica de las formas de expresión visual, debido a su marcada polisemia, que dificulta la expresión de significados precisos. Sobre este hecho Magariños dice sobre las imágenes y materiales visuales que tienen "características... a partir de las cuales un intérprete puede...", con lo cual quien produce la significación es el interpretante intérprete (Magariños de Morentin, J., 2002, Cap. 12) por lo que el "lenguaje pictórico" y el "lenguaje fotográfico" debe entenderse sólo en el sentido metafórico.

Los mensajes figurativos no funcionan como los códigos simbólicos, de la lingüística, ya que no comprometen habilidades hermenéuticas (interpretativas) de los destinatarios con un sistema de signos convencionales (alfabéticos o fonéticos). Primero se seleccionan los significados de un producto visual y una huella del físico real, es decir, una forma directamente motivada por su contenido sin la interposición de un signo intermedio convencional. Estas imágenes mantienen relaciones de representación necesaria con la realidad. Tratan de estimular previa y directamente la esfera emocional del receptor, que es de quien depende su vida existencial y no de su competencia y habilidades técnicas, como la alfabetización y / o el conocimiento de un idioma hablado.

Por el contrario, el producto lingüístico, escrito u oral, se compromete en primer lugar, con el componente racional de la decodificación y atribución de significado y solo en un momento determinado, eventualmente, involucra la esfera emocional del destinatario.

Esta inversión entre el momento del procesamiento racional y la del impacto en la esfera emocional coloca al producto visual en un término inferior, desde un punto de vista de efectividad comunicativa.

Es obvio que el producto lingüístico también está sujeto a la incertidumbre, entendido como el riesgo de una degradación subjetiva, pero esta es significativamente menor que el producto visual. De hecho, mientras que la erosión subjetiva de un producto la lingüístico tiene lugar ex post con respecto a su decodificación, la "manipulación" subjetiva de un producto visual tiene lugar simultáneamente con su percepción sensorial. El mensaje visual se consume, por así decirlo, en el acto inmediato de su percepción y permanece confinado en él.

Las experiencias sensoriales del receptor, en otras palabras, se podría afirmar que el emisor interpreta el mensaje lingüístico, mientras que el mensaje visual lo interpreta el destinatario. El significado del producto lingüístico es la combinación de los signos que la componen, en él se codifica la intención del su emisor, mientras que el significado del producto visual y la combinación de las experiencias previas del destinatario, que son independientes completamente de las intenciones del emisor, y son codificadas por el receptor. Sintéticamente, mientras que un mensaje lingüístico lo conoces, un mensaje 


\section{TECNOLOGÍAS DE LA INFORMACIÓN Y LOS MENSAJES EN LOS NUEVOS}

ESPECTROS DEL CONFLICTO.

visual lo estás experimentando. Una historia se puede contar, una imagen se puede describir a lo sumo. Pero describir una imagen significa traducir una impresión sensorial a un código lingüístico, que equivale a generar un mensaje completamente nuevo, original.

2) La segunda razón es de carácter local, y se refiere a la característica cultural del medio rural afgano. Ya hemos descrito el nivel de alfabetización tecnológica, casi residual, y de la dificultad de acceso en ese contexto a los sistemas de medios de comunicación. Nos referimos a las empresas tradicionales que no han desarrollado una imaginación colectiva visual y que no cuenta con los recursos iconográficos de la civilización occidental moderna, en relación a la imagen, aquellas que respetan la tradición sobre la prohibición de la representación, establecida por la tradición sunita y descendiente de lo que se había profetizado, que afirma el que se atreviera a falsificar la obra de Dios no será aceptado en el paraíso. La prohibición de representar la creación divina a través de imágenes formaliza un tabú muy antiguo, de origen oscuro, pero históricamente de gran importancia en los entornos del islam tradicional sunita. Hoy, donde los medios modernos de comunicación masiva (visual), fundamentalmente de carácter occidental, han entrado en las casas de los musulmanes, esa prohibición, aunque formalmente todavía válida, ha perdido gran parte de su eficacia. En las provincias rurales, en cambio, los afganos que aún no han sufrido una penetración completa de los medios de comunicación visual (occidental), hace que el interdicto y la falta de educación relativa a la imagen continúen ampliamente presentes.

Se puede concluir en este aspecto que el producto visual y polisémico es poco eficaz. Su mensaje, asumiendo que se entienda correctamente, será difícil que sea asumido por su receptor.

\section{Conclusiones.}

De la información que se ha explicado con anterioridad se hace evidente que la evolución de las tecnologías de la información y de los conflictos no han ido de la mano.

Encontramos que el conflicto a lo largo de la historia es similar, entendiendo que los oponentes utilizaban sus medios bélicos de formas similares, mientras que los desarrollos de las tecnologías de la información no han significado grandes impactos en la audiencia, hasta la llegada de la primera gran revolución, la imprenta en el que se empieza a desarrollar dichos impactos, ejemplo la Leyenda Negra Española.

Con la llegada de la última revolución de las tecnologías de la información, internet, es cuando se hace patente el impacto de las mismas en los conflictos.

Nace un nuevo concepto de conflicto, la guerra híbrida, en el que la comunicación se convierte en pilar fundamental.

Y del estudio de tres ejemplos de lo que se denominan guerras híbridas se obtienen las siguientes conclusiones:

Primera, el uso de los nuevos medios de comunicación como herramienta dentro del nuevo conflicto es de carácter profesional. Se observa que, en las primeras guerras, la de Chechenia, los insurgentes no disponían del conocimiento adecuado de las capacidades de la nueva tecnología no pudiéndolas aprovechar en su totalidad. 


\section{Jacinto Gómez López}

Segunda, es necesario que la dirección de esta nueva herramienta del conflicto sea dirigida por personal que conozca profundamente los medios de comunicación y la manera de vehicular los mensajes para la obtención de los efectos deseados. Dichos efectos tienen que ser planeados con anterioridad para la producción de los productos mediáticos exactos, en cuento a su soporte y a su narrativa.

Tercera, es necesario adecuar el mensaje al contexto social al cual se dirige. Es evidente que la alfabetización digital no ha llegado a todas las regiones del mundo por igual, por lo que el uso de la información como arma, se encuentra supeditada al nivel de conocimiento de las nuevas tecnologías por parte de la población de la zona.

Para finalizar se puede afirmar que actualmente la información se ha convertido en un activo para los contendientes de los diversos conflictos. El acierto de su uso, tanto en soportes como en los mensajes, contribuirá a la aceptación de las tesis de cada uno de ellos en dichos conflictos.

Bibliografía

[DoD], D. o. (marzo de 2005). Air University. Recuperado el 3 de febrero de 2019, de http://www.au.af.mil/au/awc/awcgate/nds/nds2005.pdf

Ames, C. (2003-2004). Facultad de Humanidades y Ciencias de la Educación de la Universidad Nacional de la Plata. Recuperado el 7 de febrero de 2019, de http://www.memoria.fahce.unlp.edu.ar/art_revistas/pr.3279/pr.3279.pdf

Ballesteros Martín, M. Á. (13 de septiembre de 2017). Instituto Español de Estudios Estratégicos. Recuperado el 7 de febrero de 2019, de http://www.ieee.es/Galerias/fichero/docs_analisis/2017/DIEEEA51 2017_Estrategia_Daesh_Revista_Dabiq_MABM.pdf

Canada, I. a. (15 de febrero de 2015). The UN Refugee Agency. Obtenido de https://www.refworld.org/docid/54f02a6c4.html

Carrión, F. (2016). El Mundo. Recuperado el 7 de febrero de 2019, de https://www.elmundo.es/television/2016/10/17/5802766d46163f2b6c8b4652.html.

Colom Piella, G. (24 de octubre de 2014). Instituto Español de Estudios Estratégicos. Recuperado el 8 de febrero de 2019, de http://www.ieee.es

Dyer, G. (2015). Que no cunda el pánico. Barcelona: Librooks.

Fundéu. (2014). Fundéu. Recuperado el 7 de febrero de 2019, de https://www.fundeu.es/recomendacion/estado-islamico-de-irak-y-el-levante/

Gluck, L. B. (25 de julio de 2017). Ultima Ratio. Recuperado el 7 de febrero de 2019, de http://ultimaratio-blog.org/archives/8463

Instituto de Estadística de la Organización de las Naciones Unidas para la Educación, I. C. (2018). Banco Mundial. Obtenido de https://datos.bancomundial.org/indicador/SE.ADT.LITR.ZS

Just Terror. (2015). Dabiq, 64. 
MATTIS, J. y. (2005). Future warfare: The rise of hybrid warfare. U.S. Naval Institute Proceedings(132), 30-32. Recuperado el 7 de febrero de 2019

Moore, J. (10 de noviembre de 2016). NewsWeek. Obtenido de http://www.newsweek.com/isis - confirms - death - media - emir - abu mohammad - al - furqan - 508658

Pérez Lagarcha, A. (2009). Unirioja. Recuperado el 7 de febrero de 2019, de https://dialnet.unirioja.es/descarga/articulo/3138193.pdf

Pizarroso Quintero, A. (2009). Diplomáticos, propagandistas y espías. Estados Unidos y España en la segunda guerra mundial: Información y Propaganda. Madrid: Consejo Superior de Investigaciones Cientificas. Recuperado el 7 de febrero de 2019

Programme, U. N. (2018). United Nations . Obtenido de http://hdr.undp.org/en/countries/profiles/AFG

SCHULZE SCHNEIDER, I. (2008). La Leyenda Negra de España. Propaganda en la Guerra de Flandes" (1566-1584). Madrid: Editorial Complutense. Recuperado el 7 de febrero de 2019

Simon, L. (3 de mayo de 2016). War on the Rocks. Recuperado el 8 de febrero de 2019, de http://warontherocks.com/2016/05/a-european-perspective-on-anti-accessareadenial-and-the-third-offset-strategy/

The Failed Crusade. (2014). Dabiq, 22.

The Murtadd Brotherhood. (2016). Dabiq, 4-5.

The Return of Khilafah. (2014). Dabiq, 35.

The Return of Khilafah. (2014). Dabiq, 12. 